\title{
Drugs, dogs, and driving: the potential for year-round thermal stress in UK vehicles
}

\author{
Anne J. Carter ${ }^{*}$, Emily J. Hall ${ }^{1}$, Sophie L. Connolly ${ }^{1}$, Zoe F. Russell ${ }^{2}$ and Kirsty Mitchell ${ }^{1}$ \\ ${ }^{1}$ School of Animal, Rural and Environmental Sciences, Nottingham Trent University, Nottingham, UK \\ ${ }^{2}$ Skinner's Pet Foods, Suffolk, UK
}

\begin{abstract}
Background: Dogs are regularly transported or housed in vehicles, with guidelines for housing dogs suggesting that the ambient temperature should be maintained between $15^{\circ} \mathrm{C}$ and $24^{\circ} \mathrm{C}$. Veterinary drugs are routinely stored and carried in vehicles providing ambulatory veterinary care. Non-refrigerated medications typically require storage between $8^{\circ} \mathrm{C}$ and $25^{\circ} \mathrm{C}$.

Aim: This study aims to investigate the potential for thermal stress associated with vehicular storage and transportation of drugs and dogs in a temperate climate, such as the United Kingdom.

Methods: The study used data loggers to continuously record internal temperatures of four vehicles at 15-minute intervals over a two-year period, to investigate the effect of seasonality and time of day on the internal car temperature.

Results: The internal car temperature ranged from $-7.4^{\circ} \mathrm{C}$ to $54.5^{\circ} \mathrm{C}$ during the study period. Temperatures fell below $8^{\circ} \mathrm{C}$ every month, except June and July. The internal car temperature exceeded typical drug storage recommendations $\left(>25^{\circ} \mathrm{C}\right)$ during every month, and exceeded the canine thermoneutral zone $\left(>35^{\circ} \mathrm{C}\right)$ from April to September. Peak temperatures occurred between 14:00 and 17:00 hours.

Conclusion: The results demonstrate the year-round potential for thermal stress of both dogs and drugs left in cars. Public awareness campaigns highlighting the risks of leaving dogs in hot cars are typically launched in late spring, but should consider launching earlier in light of these findings. Veterinary surgeons transporting drugs should take measures to ensure that drugs are stored within the manufacturer's temperature range year-round. This will limit the potential for drug degradation and decreased efficacy.

Keywords: Car temperature, Drug storage, Dog transport, Thermal stress.
\end{abstract}

\section{Introduction}

Cars have become an essential part of modern-day life, with $78 \%$ of household in the UK owning at least one vehicle (ONS, 2019). Ambulatory veterinary and medical professionals may use vehicles to transport both patients and pharmaceutical products. Over $78 \%$ of dog owners in the UK regularly use their vehicles as a means of transporting or housing dogs for working, showing, and companionship roles (Dotson and Hyatt, 2008). In a survey of over 28,000 dog owners, $21 \%$ reported having left their dog unattended in a car for over 20 minutes (AA, 2015). The interior temperature of a vehicle can change rapidly with an average increase of $1.8^{\circ} \mathrm{C}$ per 5-minute interval (McLaren, 2005), and is, therefore, a threat to both the welfare of the animals and stability of any medication contained within the vehicle (Valenzuela et al., 1989; Gammon et al., 2008; Skånberg et al., 2018). While studies have investigated livestock transport and the potential impact of thermal stress, there is a lack of comparable research on thermal transportation conditions for pet dogs (Mitchell and Kettlewell, 2008; Mitchell et al., 2010). Existing studies have looked at a short time period in the USA (McLaren, 2005; Grundstein et al., 2009; Duzinski et al., 2014) or looked at the impact of specific storage methods for drugs, such as insulated containers in cars housed predominantly in a garage or car port for a single year (Haberleitner et al., 2014). Comprehensive, year-round studies recording the internal temperatures from cars parked in open, unshaded car parks within a temperate climate, such as the UK, are currently lacking.

Calls to the Royal Society for the Prevention of Cruelty to Animals (RSPCA) to report dogs trapped in hot vehicles in the UK peaked at over 10,000 calls during 2014. This prompted the 2015 launch of an intensive educational campaign led by veterinary, charity, and canine welfare organizations "Dogs die in hot cars" (Duggal, 2018). Despite this annual campaign, the number of calls to the RSPCA about dogs in hot cars has risen from 7187 in 2016, to almost 8300 in 2018, suggesting that dog owners are not heeding the warning message (BVA, 2019). A similar increase in calls to the RSPCA (Australia) regarding dogs in hot cars has been 
reported in Australia, with the number of calls more than doubling from 2009 to 2017 (Shih et al., 2019).

While dogs are known to tolerate a wide range of temperatures, guidelines for housing dogs suggest the ambient temperature should remain between $15^{\circ} \mathrm{C}$ and $24^{\circ} \mathrm{C}$ (Home Office, 2014). The canine thermoneutral zone varies depending on the breed with coat length, body size, and activity levels, all impacting the range (National Research Council, 2006). A range of approximately $16^{\circ} \mathrm{C}-24^{\circ} \mathrm{C}$ is suggested for Greyhounds (Hales and Dampney, 1975), and $-25^{\circ} \mathrm{C}$ to $10^{\circ} \mathrm{C}$ suggested for Inuit Sled dogs (Gerth et al., 2010). The critical temperatures proposed for dogs in general range from $15^{\circ} \mathrm{C}$ to $20^{\circ} \mathrm{C}$ at the lower end, to $30-35^{\circ} \mathrm{C}$ at the upper end (Hammel et al., 1958). Beyond $35^{\circ} \mathrm{C}$, panting is triggered to dissipate heat, with posture changes exposing more surface area to enable greater heat loss through radiation or conduction (Hammel et al., 1958). In enclosed vehicles, dangerous microclimate conditions can develop due to the lack of air movement, and this can result in reduced latent heat exchange for humans and animals (Grundstein et al., 2017). While dogs can still effectively thermoregulate at $35^{\circ} \mathrm{C}$, they use panting to enable evaporative heat loss, which becomes ineffective in high relative humidity, as ambient temperature approaches body temperature or when there is limited air movement, such as within an enclosed vehicle (Hemmelgarn and Gannon, 2013). However, in brachycephalic dogs, the inability to effectively cool through panting can result in dogs overheating at ambient temperatures as low as $21-22^{\circ} \mathrm{C}$ (Lilja-Maula et al., 2017).

Veterinary drugs are routinely carried in vehicles for farm animals and equine veterinary care. Nonrefrigerated medications typically require storage between $8^{\circ} \mathrm{C}$ and $25^{\circ} \mathrm{C}$ (BSAVA, 2019). Above or below this temperature range, the drugs may lose their efficacy, may no longer be covered under license, and might need to be destroyed (BSAVA, 2019). A study investigating how storage affects human medicines found that the stability of some drugs is compromised at temperatures above $25^{\circ} \mathrm{C}$, and cyclical variation between hot and cold increases the speed of drug breakdown in some preparations (Valenzuela et al., 1989; Gammon et al., 2008). Recent research focusing on veterinary vehicles in the USA found that $63 \%$ and $95 \%$ of internal temperature readings exceeded $25^{\circ} \mathrm{C}$ in Texas and Nebraska, respectively, but the evaluation was limited to a 4-month summer period and lacked the seasonal change or minimum temperatures (Ondrak et al., 2015). There is limited research relating specifically to UK vehicles.

Climate change has led to a rise in global temperatures at a rate which is constantly accelerating (Mora et al., 2017). In the first half of the 20th century, it was estimated that the average global temperature had risen by $0.2^{\circ} \mathrm{C}$, and that by the year 2100 the average global temperature will increase by up to $4.9^{\circ} \mathrm{C}$ (Karl and Trenberth, 2003). Heat waves are predicted to become more frequent and more extreme (Mora et al., 2017), with both human and canine deaths due to heatrelated illness likely to increase (House of Commons Environmental Audit Committee, 2018). Societies need to be prepared to mitigate the risk associated with rising global temperatures; therefore, a better understanding of the risks associated with vehicular use for both medication and dog transport is essential.

The aim of this study is to investigate the effect of seasonality and time of day on the internal car temperature using observational data collected over a two-year period.

\section{Materials and Methods}

\section{Selection of vehicles}

Vehicles were opportunistically chosen from staff working at a rural university campus in the East Midlands, UK. Four privately owned cars were used for the study, consisting of three Ford Fiestas (dark red, dark blue, and white in color) and one Volvo Estate V60 (silver in color), reflecting popular car models and colors in the UK (What Car?, 2019). Each car was used over different periods of time between January 2017 and December 2018, depending on the availability of the vehicle (minimum 7 months, maximum 18 months). The cars were typically parked at the campus between 08:00 and 17:00 hours, with limited or no shade. Three of the cars (two Fiestas and the Volvo) belonged to practicing veterinary professionals, so were subject to some overnight use. To reflect the random and variable parking practices of ambulatory veterinary staff and dog owners, no restrictions were placed on the parking location of the cars in this study. During weekdays, the cars were typically parked at the campus at various orientations to the sun, alongside other vehicles, and in either full sun or partial shade, depending on parking availabilities; overnight and during weekends the cars were also parked at private residences. All cars were located in the East Midlands, UK, for the duration of the study.

\section{Internal car temperature recording}

The EL-USB-2 data logger (Lascar Electronics Ltd, UK) continuously recorded the internal temperature of each car. The data loggers were located in the boot compartment shielded from direct sunlight, reflecting where dogs or medications would typically be housed. The data loggers recorded readings at 15-minute intervals, 24 hours per day. Data were read from the loggers every month by attaching the logger to a laptop; this allowed regular checks to the logger storage and battery function minimizing data loss. As the purpose of this study is to measure the internal temperature of cars being driven and parked, reflecting normal commuting and personal usage, no attempts were made to control for sun exposure during the summer or the use of heaters during the winter. Weekend and holiday data were included to reflect all periods when dogs 
may travel in cars or when drugs may be stored due to weekend work.

\section{Ambient temperature}

Ambient temperature data for the study period were obtained from the study site using the Brackenhurst Weather Station, located at $53^{\circ} 3^{\prime} 41.62^{\prime \prime} \mathrm{N}$, $0^{\circ} 57^{\prime} 49.75^{\prime \prime} \mathrm{W}$, to provide an indication of ambient temperature throughout the study period.

\section{Data analysis}

The data were cleaned and categorized using MS Excel (Office 365) and then analyzed using SPSS v25 (IBM Inc. Chicago, IL). Three critical temperature thresholds were used to categorize and then analyze the internal car temperature data. A minimum temperature of $8^{\circ} \mathrm{C}$ is required to store the majority of non-refrigerated injectable medications (BSAVA, 2019); therefore, the lower critical temperature threshold was $<8^{\circ} \mathrm{C}$. The maximum temperature permitted for storage of nonrefrigerated medications is typically $25^{\circ} \mathrm{C}$ (BSAVA, 2019); additionally, $25^{\circ} \mathrm{C}$ exceeds the upper limit recommended for housing dogs (Home Office, 2014). Therefore, $>25^{\circ} \mathrm{C}$ was the intermediate critical threshold temperature. The upper critical temperature threshold was set at $>35^{\circ} \mathrm{C}$, as this temperature is the upper limit for most dogs' thermoneutral zones (Hammel et al., 1958). While dogs can still thermoregulate at this temperature, within the confines of a car, the lack of ventilation will escalate the increase in ambient temperature, meaning the limits of panting as a means of cooling will be quickly exceeded.

Descriptive statistics were carried out on the internal car temperature data to establish minimum, maximum, and mean monthly temperatures. The percentage of readings recorded each month and during each hourly interval that fell under $8^{\circ} \mathrm{C}$, over $25^{\circ} \mathrm{C}$, and over $35^{\circ} \mathrm{C}$ were calculated, with 95\% confidence intervals (95\% CI) calculated using EpiTools Epidemiological Calculators (Ausvet, 2019). Additionally, the percentage of days in each month where at least one car temperature was found to exceed each of the three critical temperature thresholds was calculated.

\section{Ethical approval}

Ethical approval was granted by the Nottingham Trent University School of Animal, Rural and Environmental Sciences Ethical Approval Group under study reference ARE469.

\section{Results}

The ambient temperature for the campus location ranged from $-6.3^{\circ} \mathrm{C}$ to $32.1^{\circ} \mathrm{C}$ during the study period; these extreme temperatures were recorded in February 2018 and July 2018, respectively. A total of 150,860 individual internal vehicle temperatures were recorded, with the number of readings per hour ranging from 6,276 to 6,294 and the number of readings per month ranging from 7,397 to 17,857 (see Table 1). The highest internal car temperature recorded was $54.5^{\circ} \mathrm{C}$ in June 2018 and the lowest temperature recorded was $-7.4^{\circ} \mathrm{C}$ in February 2018 (see Table 1 for descriptive statistics).

The internal car temperature fell below $8^{\circ} \mathrm{C}$ every month, except June and July, with over $50 \%$ of readings falling below this threshold from January to March (see Fig. 1). The internal car temperature dropped below $8^{\circ} \mathrm{C}$ for $80 \%$ of days from December to April (see Figure 2). Conversely, the internal car temperature exceeded $25^{\circ} \mathrm{C}$ every month. Over $15 \%$ of the total readings exceeded $25^{\circ} \mathrm{C}$ between May and August (Fig. 1). The internal car temperature exceeded $25^{\circ} \mathrm{C}$ for over $65 \%$ of days from May to August, peaking in July ( $96.8 \%$ of days). The internal car temperature exceeded $35^{\circ} \mathrm{C}$ from April ( $10.0 \%$ of days) to September $(48.3 \%$ of days), with

Table 1. The minimum, maximum, and mean (with standard deviation) internal car temperatures and total number of measurements recorded by month across a two-year period (2017-2018).

\begin{tabular}{ccccc}
\hline Month & $\begin{array}{c}\text { Minimum internal car } \\
\text { temperature }\left({ }^{\circ} \mathbf{C}\right)\end{array}$ & $\begin{array}{c}\text { Maximum internal car } \\
\text { temperature }\left({ }^{\circ} \mathbf{C}\right)\end{array}$ & $\begin{array}{c}\text { Mean internal car } \\
\text { temperature }\left({ }^{\circ} \mathbf{C}\right)\end{array}$ & Number of readings \\
\hline January & -3.5 & 28.1 & $6.25 \pm 3.87$ & 7,397 \\
\hline February & -7.4 & 30.2 & $5.97 \pm 5.16$ & 7,205 \\
\hline March & -5.0 & 32.5 & $8.29 \pm 5.90$ & 8,923 \\
April & -1.5 & 41.0 & $12.25 \pm 6.08$ & 11,517 \\
May & 0.5 & 52.0 & $18.01 \pm 8.01$ & 12,722 \\
June & 8.0 & 54.5 & $20.72 \pm 7.33$ & 14,435 \\
July & 10.5 & 54.0 & $21.99 \pm 7.26$ & 14,879 \\
August & 6.5 & 50.0 & $19.73 \pm 6.03$ & 15,580 \\
\hline September & 2.5 & 42.0 & $15.80 \pm 4.89$ & 17,088 \\
October & -1.0 & 34.0 & $14.22 \pm 4.53$ & 17,857 \\
\hline November & -3.5 & 29.0 & $11.24 \pm 5.32$ & 12,621 \\
\hline December & -6.5 & 27.5 & $7.76 \pm 5.48$ & 10,636 \\
\hline
\end{tabular}


$56.5 \%$ of days and $5.9 \%$ of the total readings exceeding this threshold in July (Figs. 1 and 2).

The percentage of internal car temperature readings exceeding each of the critical thresholds during each hourly interval is shown in Figure 3. The interval from 05:00 to 06:00 had the highest percentage of total readings below $8^{\circ} \mathrm{C}(33.2 \%, 95 \%$ CI $32.8-34.41)$.

The interval from 15:00 to 16:00 had the highest percentage of total temperature readings over $25^{\circ} \mathrm{C}$ (24.9\%, 95\% CI 23.8-26.0); however, the interval from 16:00 to 17:00 had the highest percentage of total temperature readings over $35^{\circ} \mathrm{C}(6.3 \%, 95 \%$ CI $5.7-$ 6.9). The highest temperature $\left(54.5^{\circ} \mathrm{C}\right)$ was recorded at 16:57 in June 2018. Between 21:00 and 08:00 there were no readings over $35^{\circ} \mathrm{C}$ recorded, while there were readings over $25^{\circ} \mathrm{C}$ recorded from 07:00 through to 01:00 and between 02:00 and 03:00 which included some vehicle heater use during overnight travel. The time of the peak internal car temperature recorded each month is shown in Figure 4.

\section{Discussion}

This study demonstrates the potential for thermal stress associated with transporting both pharmaceutical preparations and dogs within cars in a temperate climate, such as the UK. The internal car temperatures exceeded $25^{\circ} \mathrm{C}$ every month and dropped below $8^{\circ} \mathrm{C}$ every month, except June and July. The time of day also impacted the internal temperature of the car. In the UK, both humans and dogs are typically advised to avoid exercising around midday to reduce the risk of heatrelated illness (NHS, 2018; Blue Cross, 2019); however, the peak internal car temperatures occurred between 14:00 and 17:00, with the highest temperature of the study recorded at 16:57 in June. While Al-Kayiem et al. (2010) found the peak temperature to occur between 12:30 and 14:30, measurements were only taken for a three-day period on one vehicle, highlighting the importance of long-term monitoring and geographical variations. The time of the peak temperature varied by month with earlier peak temperatures in spring (MarchMay) and autumn (September-November). The internal temperature in this study reached over $35^{\circ} \mathrm{C}$ between 08:00 and 21:00, demonstrating that while early mornings are generally cooler, with temperatures rising through the day, there is no consistently "safe" time of day for vehicular storage. In addition, vehicle temperatures dropped below $8^{\circ} \mathrm{C}$ at every time period, suggesting that drug stability and dog comfort may be compromised at any time of day during the cooler winter months.

Pharmaceutical preparations stored in a car are at risk of exceeding their licensed storage temperature limits all year round in the UK. In a previous study,

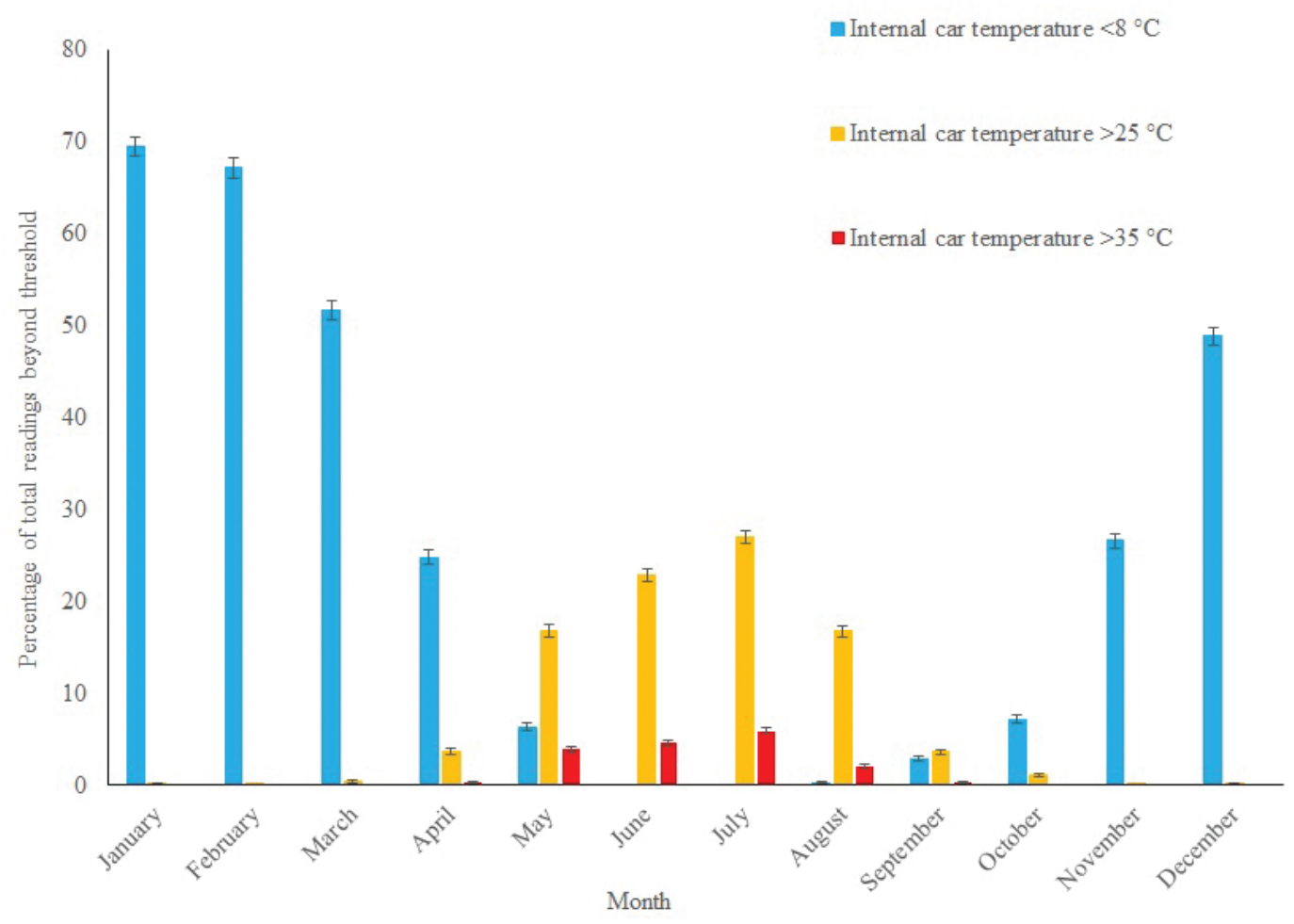

Fig. 1. Percentage (\%) of internal car temperature readings exceeding the three critical temperature thresholds (pale blue $=<8^{\circ} \mathrm{C}$, yellow $=>25^{\circ} \mathrm{C}$, red $=>35^{\circ} \mathrm{C}$ ) within each month. Error bars show the $95 \% \mathrm{CI}$. 


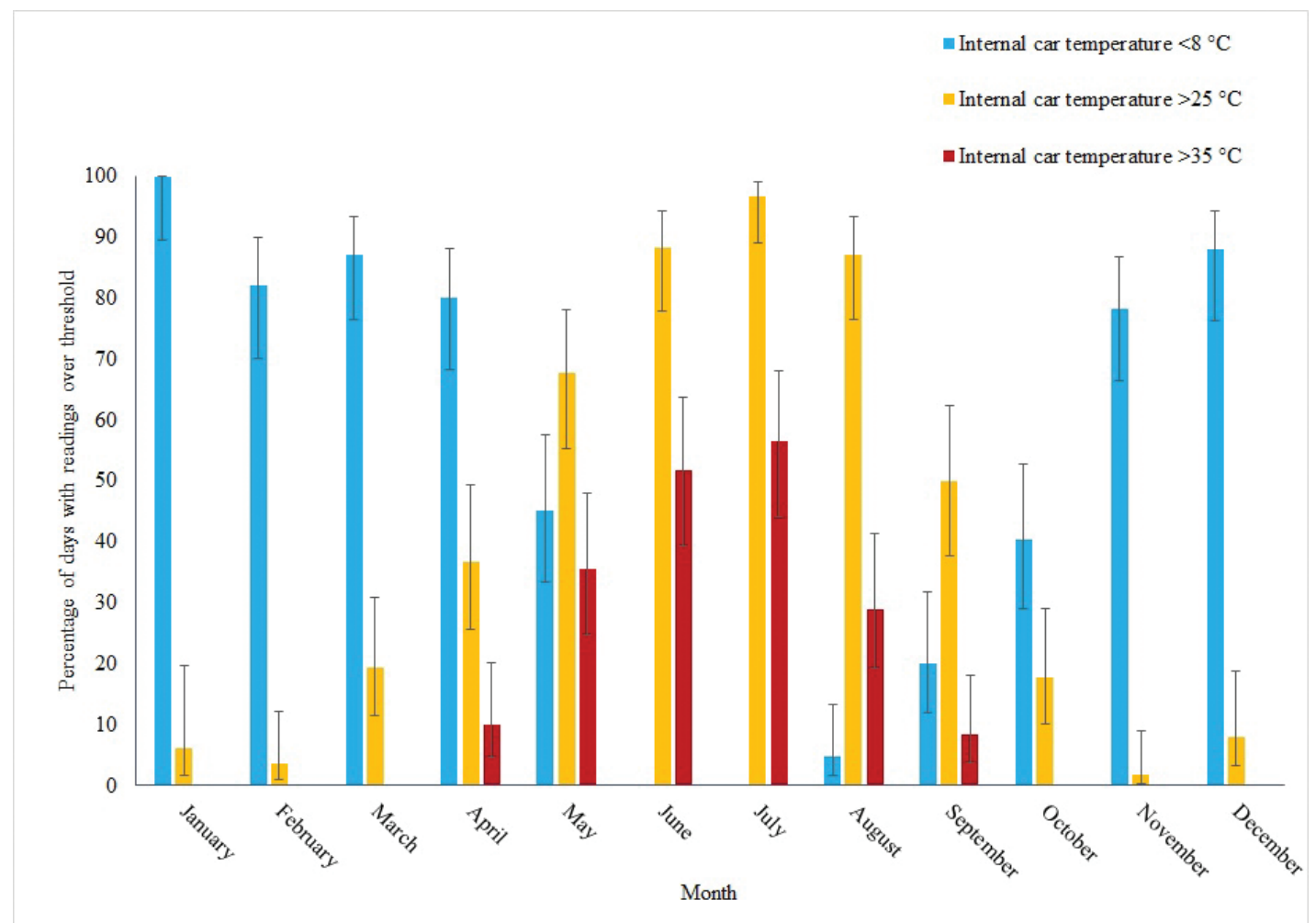

Fig. 2. Percentage (\%) of days with an internal car temperature reading exceeding the three critical temperature thresholds (pale blue $=<8^{\circ} \mathrm{C}$, yellow $=>25^{\circ} \mathrm{C}$, red $=>35^{\circ} \mathrm{C}$ ) within each month. Error bars show the $95 \% \mathrm{CI}$.

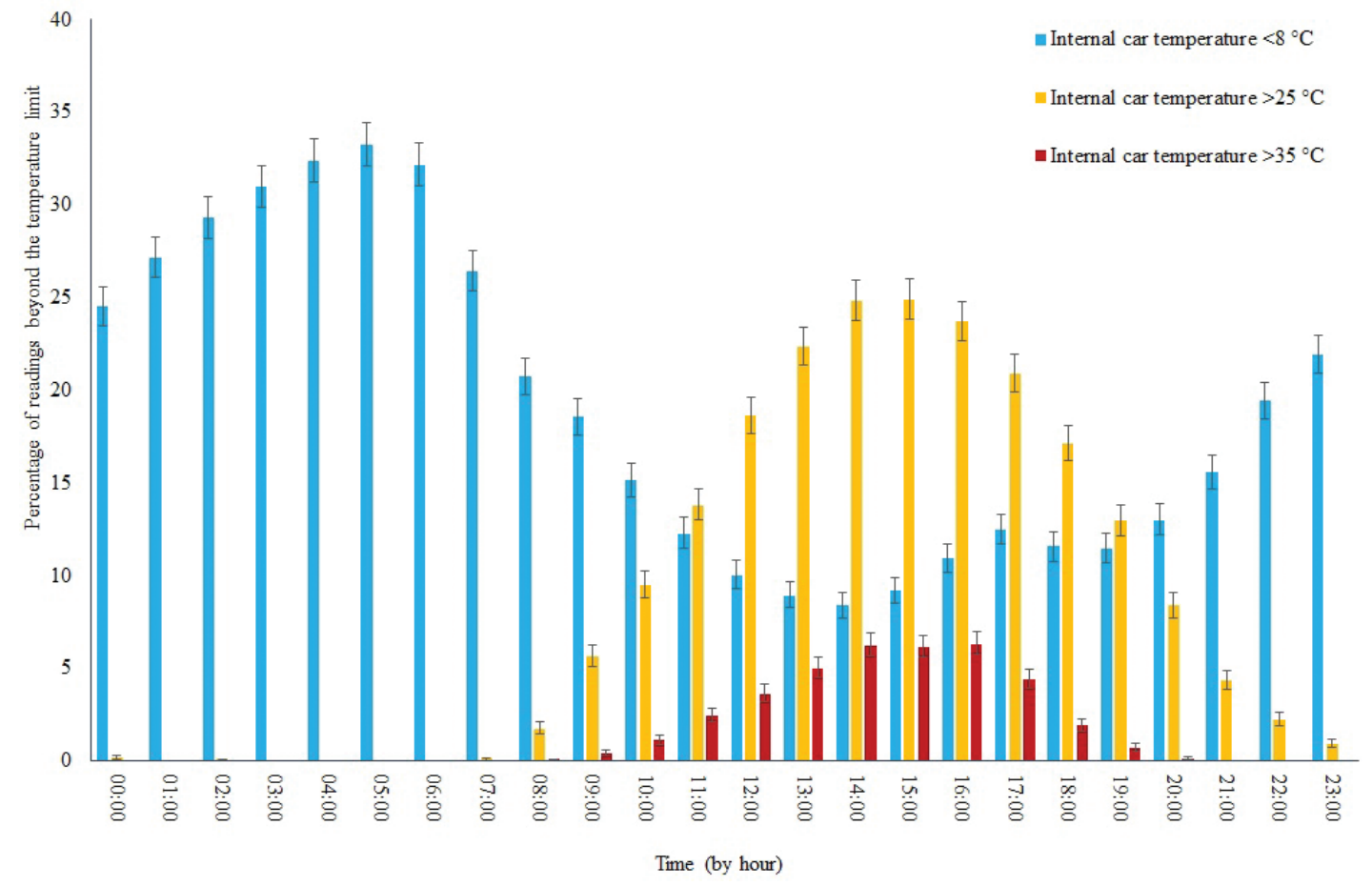

Fig. 3. Percentage (\%) of internal car temperature readings exceeding the three critical temperature thresholds (pale blue $=<8^{\circ} \mathrm{C}$, yellow $=>25^{\circ} \mathrm{C}$, red $=>35^{\circ} \mathrm{C}$ ) within each hourly interval. Error bars show the $95 \%$ CI. 


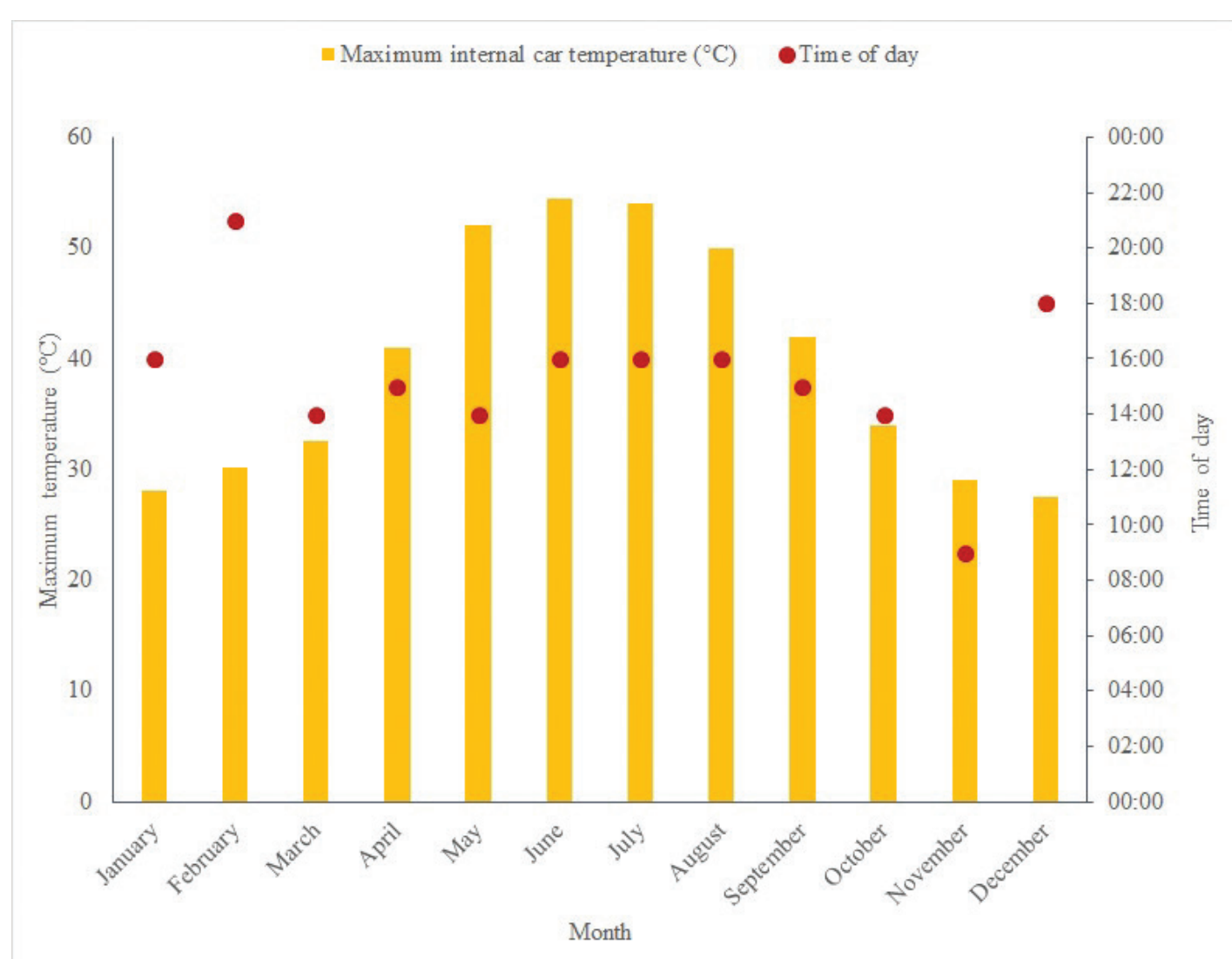

Fig. 4. Peak internal car temperatures recorded by month (yellow bars), and plotted against the time the peak temperature occurred (red circle)

veterinary practice vehicles were monitored in the USA, with $70.4 \%$ of Nebraskan and $95.0-\%$ of Texan internal vehicle temperatures recorded exceeding $25^{\circ} \mathrm{C}$ between May and September (Ondrak et al., 2015). The maximum internal vehicle temperature recorded by Ondrak et al. (2015) was $54.4^{\circ} \mathrm{C}$, which is similar to the maximum internal vehicle temperature recorded in this study $\left(54.5^{\circ} \mathrm{C}\right)$.

The stability of drugs stored within both emergency room and emergency service vehicles was tested, with $10 \%$ drug degradation occurring within one month of storage in a vehicle for some injectable preparations (De Winter et al., 2013). Cyclical heating can accelerate drug degradation, with some preparations becoming unstable within 14 days during a study simulating temperature fluctuations in emergency vehicles (Gammon et al., 2008). The consequences resulting from the use of emergency drugs with reduced efficacy following inappropriate storage are potentially fatal (De Winter et al., 2013). While previous studies have focused on the effect of temperature variation on the stability of drugs used primarily in critical care settings, ambulatory veterinary vehicles may also be carrying more routine preparations, such as antimicrobials. The thermal stability of antibiotics was researched in relation to drug residues in meat and the effects of cooking (Svahn and Björklund, 2015). While their study reported a high level of thermal stability for many of the beta-lactams and fluoroquinolones investigated, several drug concentrations (including cefuroxime, amoxicillin, and penicillin G) were decreased by around $10 \%$ at $50^{\circ} \mathrm{C}$, and doxycycline had degraded to around $20 \%$ concentration at this temperature (Svahn and Björklund, 2015). While their study aimed to determine whether cooking could remove drug residues, it demonstrates the potential for antibiotic degradation when stored in a hot environment. Use of antimicrobials stored in a hot vehicle could, therefore, result in under-dosing of patients, lack of drug efficacy, and potentially contribute to antimicrobial resistance. Grundstein et al. (2017) suggest that children can suffer heat-related illness in under an hour in vehicles with an initial temperature of $26^{\circ} \mathrm{C}$, and in less than 15 minutes if the temperature starts at $46^{\circ} \mathrm{C}$. While humans and dogs use different thermoregulatory mechanisms, the vehicular conditions that limit human cooling also affect canine cooling mechanisms. The internal car temperatures exceeded $35^{\circ} \mathrm{C}$ from April to September, with over $30 \%$ of days resulting in an internal car temperature over $35^{\circ} \mathrm{C}$ in May, June, and July. This highlights that while the summer months remain the period when overheating is most likely, temperatures 
exceed the upper limit for most dogs' thermoneutral zones during months outside of what are normally considered the "high risk" summer months. As lack of heat acclimatization is a risk factor for heat-related illness in dogs (Hemmelgarn and Gannon, 2013), the peak temperatures recorded in March $\left(32.5^{\circ} \mathrm{C}\right)$ and April $\left(41.0^{\circ} \mathrm{C}\right)$ are particularly concerning, as it is unlikely that UK dogs would have had an opportunity to acclimatize to heat during this period. The French Bull Dog Club of America (2019) recommends that French bulldogs are provided with air conditioning in temperatures exceeding $21^{\circ} \mathrm{C}$, other brachycephalic dogs, such as bulldogs, have been demonstrated to overheat at room temperatures of just $21-22^{\circ} \mathrm{C}$ (LiljaMaula et al., 2017). Internal car temperatures exceeded $25^{\circ} \mathrm{C}$ throughout the year in this study, highlighting the increased risk of vehicular-induced heat-related illness in brachycephalic breeds, even in the winter months and those traditionally perceived as colder.

The risk to dogs is not limited to just being left unattended in a hot car. While many modern cars are equipped with air conditioning, older models may only have air vents and many pick-up style trucks and vans have separate storage compartments which lack ventilation mechanisms. Dogs transported in such vehicles could, therefore, be exposed to dangerously high internal vehicle temperatures during prolonged periods of transport and are especially at risk if the vehicle is stationary in traffic or while queuing in full sun. Even dogs transported in purpose-built vehicles with climate control can be at risk if the vehicle loses power or develops a fault. Almost a quarter of service dog deaths in one study were found to be due to heatrelated illness (Stojsih et al., 2014). Three quarters of these deaths were due to being confined in a hot vehicle, with over a third occurring due to a vehicle malfunction that allowed the internal temperature to reach a fatal temperature without notifying the dog handler (Stojsih et al., 2014).

Heatwave alerts are triggered by the Met Office from 1 June to 15 September, or when the daytime threshold exceeds $30^{\circ} \mathrm{C}$ and the nighttime threshold exceeds 15 ${ }^{\circ} \mathrm{C}$ (Met Office, 2017). As the internal temperature of a car can reach dangerously high levels in relatively cool ambient temperatures, additional warning campaigns are run to try and increase public awareness. Welfare organizations, including the RSPCA and Dogs Trust, alongside the British Veterinary Association publish yearly campaigns including "Dogs Die in Hot Cars," to deter owners from leaving dogs in cars during the hotter summer months (Duggal, 2018). However, these campaigns typically begin in May (BVA, 2019), and with temperatures exceeding $35^{\circ} \mathrm{C}$ from April to September arguably, the message needs to be shared earlier in the year with a potential need for a year-round awareness campaign.

As a result of climate change, the frequency and intensity heatwaves are becoming increasingly irregular, making estimations on their intensity and duration very difficult to predict (Lowe et al., 2011). Rising ambient temperatures will increase the threat vehicular storage poses to both canine safety and drug stability. In addition, the increasing unpredictability and likelihood of unseasonably high and low temperatures increases the likelihood of problems occurring if dogs and drugs are left in vehicles during months ordinarily considered "safe."

The vehicles used in this study were generally kept in an unshaded car park, reflecting the lack of consistent shading routinely available in UK car parks. The three meteorological parameters shown to drive internal vehicular temperature are the air temperature, wind speed, and solar radiation (Horak et al., 2017). Solar radiation has been shown to have the most profound effect on internal vehicle temperature in both winter and summer months (Grundstein et al., 2009). Even cars initially parked in the shade may become exposed to high levels of thermal radiation as the sun's position changes throughout the day. Partially opening the window has been shown to have little effect on reducing the internal temperature to a safe level (Al-Kayiem et al., 2010) and has no impact on the rate of temperature increase (McLaren, 2005). The use of sun shading on windows to limit car internal temperature has been demonstrated to have a significant effect (Al-Kayiem et al., 2010), but this requires further investigation to determine the efficacy of different shading materials and shade positioning within the car, and the degree to which the overall temperature could be reduced.

\section{Limitations}

The cars used in this study were not subjected to any modifications or restrictions of use during the study period. It is highly probable that the peak internal temperatures recorded during the winter months were due to heaters being used, especially the peaks that coincide with typical staff commuting times between 09:00 and 18:00 hours and overnight travel. The effect of car color on internal temperature was not investigated, as the cars were not always parked at the same location or subjected to the same environmental conditions, such as natural shading, car park substrate, or shelter from wind. The internal car temperature was measured at only one location in this study, chosen to reflect the likely storage location of drugs and to measure the air temperature of boot space only. An important factor in the development of vehicular heat-related illness is the increased contribution of conducted heat from surfaces in contact with the body, such as safety seats to children (Grundstein et al., 2017), and from the boot lining to dogs trapped in the boot area. This study recorded internal temperature at only one location within the cars, and it is highly probable that the areas of the cars, such as the dashboard, reached higher temperatures, and areas such as the footwells may have remained cooler than the temperatures recorded by the data loggers in the boot space. If dogs are transported 
unrestrained, it may be possible for them to move to cooler locations within the vehicle; however, arguably the presence of a dog within the vehicle would also contribute to further temperature elevation. This study focused exclusively on the change in ambient temperature within the vehicles. While humidity also impacts a dog's ability to thermoregulate through panting and effectively cool, the presence of a dog in the vehicle would itself impact the internal humidity, so this was not explored.

The effect of car location (shaded versus in full sun) and car park substrate (black tarmac versus pale hardcore or concrete) was not investigated in this study; however, the highest internal temperature was recorded while the car was parked on a black tarmac car park in full sun with the front windscreen facing the sun during the afternoon. Further research into the effects of car park substrate, natural sun shading, such as foliage, and cooling interventions, such as window vents, leaving the boot open and covering the car with a reflective shade is needed to determine if it is possible to prevent cars exceeding the canine thermoneutral zone limit of $35^{\circ} \mathrm{C}$. As this study demonstrates the year-round risk of thermal stress to drugs stored in veterinary or medical ambulatory vehicles, further research is required to identify suitable storage strategies to protect pharmaceutical products from both hot and cold temperatures during vehicular storage and transportation. Additional studies including more cars and other types of vehicle from around the globe could be considered to generate more robust guidance for preventing thermal stress when transporting both animals and pharmaceutical products.

\section{Conclusion}

This study demonstrates the year-round potential for thermal stress to dogs and drugs left in cars. Internal car temperatures exceeded the canine thermoneutral zone $\left(35^{\circ} \mathrm{C}\right)$ from April to September and exceeded typical drug storage recommendations $\left(8^{\circ} \mathrm{C}-25^{\circ} \mathrm{C}\right)$ during every month. Peak temperatures occurred between 14:00 and 17:00 hours from March to October, meaning late afternoon is the most dangerous time to travel with a dog in a car during the summer months. As heat-related illness can be fatal, public awareness campaigns should consider launching in April or earlier, and should potentially include warnings about the increased risk to dogs in cars in the late afternoon. Veterinary surgeons transporting drugs should ensure that they are stored in a manner that prevents both cooling and heating beyond the manufacturer's storage instructions all year round, to limit the potential for drug degradation and decreased efficacy.

\section{Authors contributors}

All authors made contributions to the conception and design of the study, collection of data, and analysis and interpretation of the results. All authors were involved in drafting and revising the manuscript and gave final approval of the version to be published. Each author agrees to be accountable for all aspects of the accuracy or integrity of the work.

\section{Conflict of interest}

The authors have no competing interests to declare.

\section{References}

AA. 2015. Leaving dogs in cars. Available via http:// www.theaa.com/newsroom/news-2015/dogs-incars-aa-dogs-trust.html (Accessed 27 August 2019).

Al-Kayiem, H.H., Sidik, M.F.B.M. and Munusammy, Y.R.A.L. 2010. Study on the thermal accumulation and distribution inside a parked car cabin. Am. J. Appl. Sci. 7, 784-789.

Ausvet. 2019. Epitools-Calculate confidence limits for a sample proportion. Available via https://epitools.ausvet.com.au/ciproportion? page $=$ CIProportion $\&$ SampleSize $=1000 \&$ Positive $=75 \& \mathrm{Conf}=0.95 \&$ m e thod $=$ $3 \&$ Digits $=2$ (Accessed 15 November 2019).

Blue Cross. 2019. How to keep dogs cool in the summer heat. Availabe via https://www.bluecross. org.uk/pet-advice/how-keep-dogs-cool-summerheat (Accessed 2 October 2019).

BSAVA. 2019. Chapter 7: correct storage of medicines, dispensary management and standard operating procedures. In BSAVA guide to the use of veterinary medicines. Eds., Nind, F. and Mosedale, P. Gloucester UK, British Small Animal Veterinary Association, pp: 26-34.

BVA. 2019. Heatwave sparks dogs in hot cars calls as reports hit three year high. Available via https:// www.bva.co.uk/news-campaigns-and-policy/ newsroom/news-releases/heatwave-sparks-dogsin-hot-cars-calls-as-reports-hit-three-year-high/ (Accessed 14 July 2019).

De Winter, S., Vanbrabant, P., Vi, N.T., Deng, X., Spriet, I., Van Schepdael, A. and Gillet, J.B. 2013. Impact of temperature exposure on stability of drugs in a real-world out-of-hospital setting. Ann. Emerg. Med. 62, 380-387.

Dotson, M.J. and Hyatt, E.M. 2008. Understanding dog-human companionship. J. Bus. Res. 61, 457466.

Duggal, G. 2018. Add your voice to the Dogs Die in Hot Cars campaign. Vet. Rec. 182, 522-523.

Duzinski, S.V, Barczyk, A.N., Wheeler, T.C., Iyer, S.S. and Lawson, K.A. 2014. Threat of paediatric hyperthermia in an enclosed vehicle: a year-round study. Inj. Prev. 20, 220-225.

French Bull Dog Club of America. 2019. French bulldog breed information. Available via https:// frenchbulldogclub.org/breedinformation/ (Accessed 5 September 2019).

Gammon, D.L., Su, S., Jordan, J., Patterson, R., Finley, P.J., Lowe, C. and Huckfeldt, R. 2008. Alteration in prehospital drug concentration after thermal exposure. Am. J. Emerg. Med. 26, 566-573. 
Gerth, N., Redman, P., Speakman, J., Jackson, S. and Starck, J.M. 2010. Energy metabolism of Inuit sled dogs. J. Comp. Physiol. B. Biochem. Syst. Environ. Physiol. 180, 577-589.

Grundstein, A., Duzinski, S. and Null, J. 2017. Impact of dangerous microclimate conditions within an enclosed vehicle on pediatric thermoregulation. Theor. Appl. Climatol. 127, 103-110.

Grundstein, A., Meentemeyer, V. and Dowd, J. 2009. Maximum vehicle cabin temperatures under different meteorological conditions. Int. J. Biometeorol. 53, 255-261.

Haberleitner, A., Schauberger, G., Horak, J. and Schmerold, I. 2014. Thermal drug storage conditions in veterinary vehicles - a one-year field study in Austria. Wien. Tierarztl. Monatsschr. 101, 110-119.

Hales, J.R.S. and Dampney, R.A.L. 1975. The redistribution of cardiac output in the dog during heat stress. J. Therm. Biol. 1, 29-34.

Hammel, H.T., Wyndham, C.H. and Hardy, J.D. 1958. Heat production and heat loss in the dog at 8-36 ${ }^{\circ} \mathrm{C}$ environmental temperature. Am. J. Physiol. Content. 194, 99-108.

Hemmelgarn, C. and Gannon, K. 2013. Heatstroke: thermoregulation, pathophysiology, and predisposing factors. Compend. Contin. Educ. Vet. 35, E4.

Home Office. 2014. Code of practice for the housing and care of animals bred, supplied or used for scientific purposes. London, UK: Williams Lea Group.

Horak, J., Schmerold, I., Wimmer, K. and Schauberger, G. 2017. Cabin air temperature of parked vehicles in summer conditions: life-threatening environment for children and pets calculated by a dynamic model. Theor. Appl. Climatol. 130, 107-118.

House of Commons Environmental Audit Committee. 2018. Heatwaves: adapting to climate change. London, UK: Environmental Audit CommitteeHouse of Commons.

Karl, T.R. and Trenberth, K. 2003. Modern global climate change. Science 302, 1719-1723.

Lilja-Maula, L., Lappalainen, A. K., Hyytiäinen, H. K., Kuusela, E., Kaimio, M., Schildt, K., Mölsä, S., Morelius, M. and Rajamäki, M.M. 2017. Comparison of submaximal exercise test results and severity of brachycephalic obstructive airway syndrome in English bulldogs. Vet. J. 219, 22-26.

Lowe, D., Ebi, K.L. and Forsberg, B. 2011. Heatwave early warning systems and adaptation advice to reduce human health consequences of heatwaves. Int. J. Environ. Res. Public Health 8, 4623-4648.

McLaren, C. 2005. Heat stress from enclosed vehicles: moderate ambient temperatures cause significant temperature rise in enclosed vehicles. Pediatrics 116, e109-e112.
Met Office. 2017. Heat-health watch. Availble via https://www.metoffice.gov.uk/public/weather/heathealth/?tab=heatHealth\&season=normal (Accessed 9 September 2019).

Mitchell, M.A. and Kettlewell, P.J. 2008. Engineering and design of vehicles for long distance road transport of livestock (ruminants, pigs and poultry). Vet. Ital. 44, 201-213.

Mitchell, M.A., Kettlewell, P.J., Villarroell, M., Farish, M. and Harper, E. 2010. Assessing potential thermal stress in pigs during transport in hot weathercontinuous physiological monitoring. J. Vet. Behav. $5,61-62$.

Mora, C., Dousset, B., Caldwell, I.R., Powell, F.E., Geronimo, R.C., Bielecki, C.R., Counsell, C.W.W., Dietrich, B.S., Johnson, E.T., Louis, L.V., Lucas, M.P., McKenzie, M.M., Shea, A.G., Tseng, H., Giambelluca, T.W., Leon, L.R., Hawkins, Ed. and Trauernicht, C. 2017. Global risk of deadly heat. Nat. Clim. Chang. 7, 501-506.

National Research Council. 2006. Physical activity and environment. In Nutrient requirements of dogs and cats. Washington, DC: National Academies Press, pp: 268-269.

NHS. 2018. Heat exhaustion and heatstroke. Available via https:/www.nhs.uk/conditions/heatexhaustion-heatstroke/ (Accessed 3 May 2020).

Ondrak, J.D., Jones, M.L. and Fajt, V.R. 2015. Temperatures of storage areas in large animal veterinary practice vehicles in the summer and comparison with drug manufacturers' storage recommendations. BMC Vet. Res. 11, 1-8. doi:10.1186/s12917-015-0561-z

ONS. 2019. Percentage of households with cars by income group, tenure and household composition: Table A47. Available via https:// www.ons.gov.uk/peoplepopulationandcommunity/ personalandhouseholdfinances/expenditure/ datasets/percentageofhouseholdswithcarsby i n c o m e grouptenureand hous e hold compositionuktablea47 (Accessed 27 August 2019).

Shih, H.Y., Paterson, M.B.A. and Phillips, C.J.C. 2019. A retrospective analysis of complaints to RSPCA Queensland, Australia, about dog welfare. Animals 9, 282. doi:10.3390/ani9050282

Skånberg, L., Gauffin, O., Norling, Y., Lindsjö, J. and Keeling, L. J. 2018. Cage size affects comfort, safety and the experienced security of working dogs in cars. Appl. Anim. Behav. Sci. 205, 132-140.

Stojsih, S.E., Baker, J.L., Les, C.M. and Bir, C.A. 2014. Review of Canine Deaths While in Service in US Civilian Law Enforcement (2002-2012). J. Spec. Oper. Med. 14, 86-91.

Svahn, O. and Björklund, E. 2015. Thermal stability assessment of antibiotics in moderate temperature and subcritical water using a pressurized dynamic 
flow-through system. Int. J. Innov. Appl. Stud. 11, 872-880.

Valenzuela, T.D., Criss, E.A., Hammargren, W.M., Schram, K.H., Spaite, D.W., Meislin, H.W. and Clark, J.B. 1989. Thermal stability of prehospital medications. Ann. Emerg. Med. 18, 173-176.
What Car?. 2019. Best-selling car colours in the UK 2018. Available via https://www.whatcar.com/ advice/buying/best-selling-car-colours-in-the-uk/ n18819 (Accessed 5 July 2019). 